\title{
"Vendo o que não se enxergava": condições epistemológicas para construção de conhecimento coletivo e reflexivo da língua(gem) em contexto escolar \\ "Seeing the unseen": epistemological conditions for the construction of collective knowledge and language reflection in a school context
}

\author{
Maria Elena PIRES-SANTOS (UNIOESTE) \\ Mariangela Garcia LUNARDELI (UNIOESTE) \\ Neiva Maria JUNG (UEM) \\ Regina Coeli Machado e SILVA (UNIOESTE)*
}

\begin{abstract}
Neste povoado não mandamos com papéis - falou sem perder a calma. E para que o senhor fique sabendo de uma vez por todas, não precisamos de nenhum alcaide nem de corregedor nem de nada disso, porque aqui não tem nada para ser corrigido. (Gabriel García Márquez 2014: 98)
\end{abstract}

\footnotetext{
*. Agradecemos à Capes/INEP pelo financiamento do Observatório de Educação: Núcleo de Pesquisa/Extensão - Formação Continuada em Leitura, Escrita e Oralidade, bem como o financiamento do Projeto Juventude e dramas de moralidade: dissonâncias nas práticas de leitura e de escrita em uma escola de periferia em Foz do Iguaçu, pelo MCTI /CNPq /MEC/Capes, coordenado pelas professores Maria Elena Pires Santos e Regina Coeli Machado e Silva respectivamente. Agradecemos também à Capes pela bolsa de pós-doutorado (PNPD), concedida a Neiva Maria Jung em seu estágio no Programa de Pós-Graduação Interdisciplinar Sociedade, Cultura e Fronteira da Unioeste.

Agradecemos ainda aos pareceristas pela leitura atenta e sugestões que contribuíram para o desenvolvimento do nosso argumento no artigo.
} 


\section{RESUMO}

Temos como objetivo discutir a construção de conhecimento em Linguística Aplicada focalizando o letramento e considerando as tensões entre o conhecimento local, o campo acadêmico e os programas governamentais como o Observatório da Educação. Descrevemos um processo de formação de professores no âmbito desse programa voltado para a Educação Básica e realizado em um colégio público da Tríplice Fronteira (Brasil) Paraguai/Argentina). Em termos teóricos e metodológicos, os resultados de nossas reflexões sobre práticas de letramento, sustentadas em inserção etnográfica, evidenciaram as possibilidades de reverter as dissonâncias daí advindas em condições epistemológicas para a construção de conhecimento coletivo, reflexivo e crítico. A língua(gem) como prática social, portanto, expressiva das lutas e diferenças entre grupos sociais, constitui um dos grandes desafios para a construção de saberes compartilhados em Linguística Aplicada.

Palavras-chave: Linguística Aplicada; epistemologia; letramento; etnografia.

\section{ABSTRACT}

Our aim was to discuss the construction of knowledge in Applied Linguistics by focusing on literacy and considering the tensions between local knowledge, the academic field, and governmental programs such as the Observatório da Educação (Education Observatory). We describe a teacher training process within the scope of this program that is geared toward Basic Education and which is conducted in a public school on the Triple Frontier (Brazil/Paraguay/Argentina). In theoretical and methodological terms, the results of our reflections about literacy practices, which are sustained by ethnographic studies, show the possibilities of reversing dissonances arising from epistemological conditions for constructing collective, reflexive, and critical knowledge. Language as a social practice, which is expressive of the struggles and differences between social groups, represents one of the great challenges for constructing shared knowledge in Applied Linguistics.

Key-words: Applied Linguistics; epistemology; literacy; ethnography. 


\section{Introdução}

Dos anos 1990 para os dias atuais, a área da Linguística Aplicada (doravante LA) passou por mudanças fundamentais nos modos de produzir conhecimento, aumentando significativamente a reflexão crítica na área, aliada a uma ampliação do seu objeto de investigação (Signorini \& Cavalcanti 1998; Cavalcanti 1996). O foco das pesquisas em LA passou a ser a presença de problemas com relevância social para exigir respostas teóricas que trouxessem benefícios sociais a seus participantes (Moita Lopes 1996), deslocando-se da ciência mãe, a Linguística, para buscar respostas/teorias em outras áreas das Ciências Sociais, como Sociologia, Antropologia, Sociolinguística, constituindo o seu caráter interdisciplinar. Neste procedimento de empréstimos, conforme Celani (1992), a LA é articuladora de múltiplos domínios do saber, em diálogo constante com vários campos do conhecimento que têm preocupação com a linguagem. Seu locus de pesquisa amplia-se da sala de aula de línguas, língua materna, estrangeira ou adicional (Schlatter \& Garcez 2012), para contextos de multilinguismo, problemas de tradução, contextos de trabalho e políticas linguísticas, "espraiando-se para outros contextos" (cf. Moita Lopes 2009: 18), como empresas, clínicas de saúde, delegacia da mulher, audiências de tribunais, etc.

Atualmente, mudanças sociais intensificadas pela chamada globalização, em tempos muitas vezes chamados de 'modernidade recente' (Rampton 2006), passaram a demandar outras perguntas, modos e paradigmas de investigação, e "o campo aplicado de estudos da linguagem enfrenta cada vez mais desafios para ser responsivo a tais mudanças" (Moita Lopes 2013: 19). Acompanhando essas mudanças, a pesquisa em LA no Brasil considera o sujeito social, em sua subjetividade ou intersubjetividade, crucial para a pesquisa, "tornando-o inseparável do conhecimento produzido sobre ele mesmo assim como das visões, valores e ideologias do próprio pesquisador. Em decorrência, questões de ética, poder e política se tornam inerentes à produção de conhecimento" (Moita Lopes 2013: 17). O próprio pesquisador, ao 'escolher' sua epistemologia ou seu campo de atuação, ou ser 'escolhido', estará se filiando a um grupo ou grupos, se posicionando e posicionando politicamente o grupo social participante da pesquisa. 
Mediante essas pressuposições teóricas e metodológicas, temos como objetivo, neste artigo, discutir a construção de conhecimento em LA focalizando o letramento, considerando as tensões entre o conhecimento local, o campo epistemológico acadêmico e os programas governamentais brasileiros para a educação básica. Para tanto, descrevemos o percurso de um projeto de formação de professores vinculado ao Observatório da Educação em um colégio estadual da Tríplice Fronteira (Brasil/Paraguai/Argentina) que atende alunos dos 6. ${ }^{\circ}$ ao 9. ${ }^{\circ}$ ano do Ensino Fundamental e do Ensino Médio. Participaram do projeto apenas alunos do Ensino Fundamental.

Considerando as tensões entre esses elementos heterogêneos, gostaríamos ainda de enfatizar por meio dos resultados desse projeto a possibilidade de qualificar as proposições governamentais que, embora pautadas em critérios universalizantes e quantitativos a respeito do letramento escolar, abriram portas para a produção de um conhecimento em LA em que todos são protagonistas, como queremos mostrar. Qualificar essas proposições implica, epistemologicamente, na construção de conhecimentos de letramento em LA, de forma não assimétrica, em trabalho colaborativo e processo de interlocução envolvendo participantes da universidade, da escola e da comunidade. Esse conhecimento compartilhado foi orientado pela pesquisa etnográfica, processo pelo qual os investigadores interagiram no campo - o Colégio onde foi desenvolvido o Programa Observatório da Educação ${ }^{1}$, como será apresentado à frente - por um período de três anos.

A experiência etnográfica a que nos referimos neste artigo identifica todas as atividades das quais participamos no cotidiano do Colégio e, como em todo processo etnográfico, não seguiu um modelo ou uma receita contendo regras. O modo como aos poucos fomos participando dessas atividades e sendo aceitos permitiu, assim, construir progressivamente um conhecimento conjunto. Não só na LA, a etnografia é mais que um método, é a própria teoria vivida (Peirano 1995). Nela estão envolvidas abordagens teóricas e analíticas que orientam o modo como

1. Desenvolvido por professores do Mestrado Interdisciplinar em Sociedade, Cultura e Fronteiras, do Curso de Letras da UNIOESTE/Foz do Iguaçu e o Núcleo Regional de Educação de Foz do Iguaçu/SEED, o Programa Observatório da Educação buscou integrar pesquisa/ensino e extensão. A equipe de pesquisa envolveu professores do Colégio Estadual, em Foz do Iguaçu, e professores e estudantes da UNIOESTE. 
se obtém as informações que costumamos chamar de dados, por meio da observação participante, bem como para a apreensão da alteridade, da singularidade e da outredade.

O artigo está organizado da seguinte forma: na primeira parte, discutimos o letramento como prática social e suas relações com os gêneros do discurso, tomados como práticas sócio-comunicativas de letramento, imersas nos processos interativos da experiência coletiva do Colégio no bairro, como se verá na terceira parte. Na segunda, apresentamos e contextualizamos o Programa Observatório da Educação, iniciativa de instrumentalização de gestão das políticas educacionais e de incentivo à formação na pós-graduação. Seguindo as orientações dadas por esse Programa, que exige a atuação em escolas com baixos índices de avaliação escolar, chegamos ao Colégio para propor e desenvolver as atividades de formação de professores. Como será evidenciado, esse Colégio foi um ponto de tensão do lugar ocupado por nós, inicialmente demandado por diferentes agentes do poder público federal. Na terceira e na quarta seções, descrevemos o processo pelo qual as condições epistemológicas para a construção de conhecimentos coletivos, nesse contexto de entrelaçamento de interesses dissonantes, se tornaram possíveis, revertendo as relações assimétricas colocadas no início pela nossa identificação como gestores dos programas governamentais.

\section{Letramento como prática social: possibilidades e perspectivas teórico-metodológicas}

Compreender práticas e relações com a língua(gem) em situações de superdiversidade (Vertovec 2007; Blommaert \& Rampton 2011) tem sido um desafio para a pesquisa, sobretudo para muitos de nós, pesquisadores, confrontados com novas exigências governamentais advindas das políticas públicas brasileiras para enfrentar o fracasso escolar, medido por critérios universalizantes e avaliado em termos de capacidades necessárias para a inserção de grupos em empregos e em atividades econômicas especializadas (Souza 2001, 2013). Aliás, essa equação, que conjuga educação e economia, foi recentemente objeto de atenção de Street (2014), no último capítulo de um livro recentemente traduzido no País. Neste livro, o autor assinala a im- 
portância de problematizar o letramento como prática social, um eixo central cujas forças, centrípetas, são o que ele chamou de governança global da educação e suas interferências locais, os contextos sociais, a escolarização, e as abordagens teóricas metodológicas que orientam as pesquisas nesse universo.

No Brasil, “[...] temos avaliado muito, e pesquisado pouco ou nada, sobre as causas e as circunstâncias que podem explicar os baixos resultados ou o fracasso das nossas crianças em leitura, os baixos níveis de letramento da população jovem e adulta" (Soares 2010: 63). Talvez mais do que pesquisar "as causas e as circunstâncias dos baixos níveis de letramento", precisamos, em primeiro lugar, problematizar as avaliações e a "[...] ancoragem massiva e focada no universo global em que se assentam e a condução, na maioria das vezes, de modo asséptico e uniformizante" (Euzébio 2011: 18).

Em segundo lugar, precisamos desafiar o "não" (Street 2010), às vezes presente em descrições para identificar grupos pela negatividade, como, por exemplo, afirmando que "eles não têm religião", "eles não têm política", "eles são "não letrados"”, ao olhar para diferentes povos, diferentes comunidades ou diferentes situações. Segundo Street (2010: 43), "como pessoas interessadas em linguagem, estamos inevitavelmente preocupados em entender a diversidade." Portanto, "do ponto de vista etnográfico, precisamos ir além e começar a perguntar: 'que outras categorias podem existir para se entender o mundo e estar no mundo [...]"' (Street 2010: 44), reconhecendo práticas sociais locais e identidades (Jung 2009) e legitimando essas práticas sociais de leitura e escrita dos diferentes grupos sociais.

Esse é o desafio dos Novos Estudos de Letramento, uma nova tradição de pesquisa que surge, a partir dos anos 1980 e 1990, por meio das pesquisas de natureza etnográfica de Heath (1983) e Street (1984). Esses dois pesquisadores reconhecem o letramento como espaço de construção da vida social (Moita Lopes 2013), espaço de diferenças culturais, presentes tanto na interação como no conteúdo do texto escrito, espaço de construção de identidades, espaço de performances (Moita Lopes 2013) e, principalmente, de legitimação de ideologias (Street 2014).

Essa mudança na tradição de estudos somente acontece no final do século $\mathrm{XX}$, quando as atividades humanas relacionadas à escrita 
passam a ser reconhecidas como objeto epistêmico no campo de estudos da linguagem. Segundo Moita Lopes (2013: 235)

[...] o grande número de publicações na última metade do século XX e o interesse internacional por melhorar o nível de escolarização é que vai construir os letramentos como uma episteme ao largo da grande preocupação que os estudos linguísticos modernistas, a partir de Saussure, tiveram com a oralidade.

Além disso, os Novos Estudos do Letramento questionam a hegemonia ocidental, evidenciando que a maioria dos projetos de alfabetização propostos pela Unesco parte de uma visão ocidental de escrita, pressupondo que todos devam ser alfabetizados pelas mesmas razões: "vamos alfabetizá-los e eles conquistarão mobilidade social, igualdade econômica e política e participação na ordem social" (Street 2014: 38). Trata-se de uma consequência da teoria da "grande divisão" entre oralidade e letramento (Goody \& Watt 2003), segundo a qual os "iletrados" são diferentes dos letrados cognitiva, social e culturalmente.

Recentemente, porém, a tendência tem sido no rumo de uma consideração mais ampla do letramento como uma prática social e numa perspectiva transcultural. Dentro dessa perspectiva, uma mudança importante foi a rejeição por vários autores da visão dominante do letramento como uma habilidade 'neutra', técnica, e a conceitualização do letramento, ao contrário, como uma prática ideológica, envolvida em relações de poder e incrustada em significados e práticas culturais específicos - que eu tenho descrito como 'Novos Estudos do Letramento'. (Street 2014: 17)

Nessa perspectiva, distante das generalizações idealizadas sobre a natureza da linguagem e do letramento, propõe-se entendimentos concretos das práticas letradas em contextos sociais reais (Barton, Hamilton \& Ivanic 2000). Para tanto, lança-se mão dos conceitos de eventos e práticas de letramento, sendo os eventos de letramento as "ocasiões em que a linguagem escrita faz parte da natureza das interações e dos processos e estratégias interpretativas dos participantes" (Heath 2001: 319), e as práticas "o comportamento e as conceitualizações sociais e culturais que conferem sentido aos usos da leitura e/ou escrita" (Street 2014: 18). 
No Brasil, o termo letramento chegou há mais ou menos 30 anos. Trata-se de um neologismo, que provém do inglês literacy, que não mantém a carga semântica de origem, uma vez que na língua inglesa o termo literacy refere-se tanto ao aprendizado de um código escrito, aqui definido como alfabetização, quanto aos usos da leitura e escrita na vida cotidiana, para nós, o letramento. Assim, o conceito de letramento encontra-se no Brasil, como em outros países como a França, em fase de "adaptação" ou de "reinvenção" (Marinho 2010: 15), não somente por se tratar de um novo conceito, que exige pesquisas para ser consolidado, mas devido às diferentes correntes epistemológicas às quais o conceito foi articulado para dar conta das práticas sociais de leitura e escrita locais.

De acordo com Kleiman (2013), nossas universidades não operam bem com questões referentes à diversidade e à reinvenção epistemológica. Para a pesquisadora, precisaríamos "sulear" o debate, a epistemologia, o que precisaria constituir nossos cursos de graduação, nossos currículos de cursos de formação de professores, "de modo que as chamadas histórias apagadas e tradicionalmente esquecidas das periferias se tornassem centrais, em vez das histórias eurocêntricas ou norte-americanas" (p. 23). Ou seja, precisamos contar e legitimar as nossas histórias, os nossos conceitos, os nossos saberes.

As pesquisas iniciais desenvolvidas sobre letramento aqui no Brasil têm em comum, segundo Soares (2010: 60), "[...] significados fortemente contextualizados no campo do ensino da língua escrita", ou seja, no campo da escolaridade.

\begin{abstract}
Aos poucos, os estudos foram se alargando para descrever as condições de uso da escrita, a fim de determinar como e quais eram os efeitos das práticas de letramento em grupos minoritários [...] os estudos já não mais pressupunham efeitos universais do letramento, mas pressupunham que os efeitos estariam correlacionados às práticas sociais e culturais dos diversos grupos que usavam a escrita. (Kleiman 1995: 17)
\end{abstract}

Atualmente, não mais olhamos para os efeitos, mas para como as pessoas se "apoderam" de letramentos particulares, enfatizando o caráter ativo do público-alvo (Street 2014). Pesquisas mostram que as pessoas absorvem práticas letradas em suas próprias convenções orais, ao invés de simplesmente repetir o que lhes é apresentado. 
No campo acadêmico, paralelamente, estaríamos em um movimento de 'ocupação' ou de 'invasão' do latifúndio do saber, segundo Marinho (2010), referindo-se também à entrada de alguns grupos sociais que antes não chegavam às universidades brasileiras, e, sobretudo, exigindo a ampliação do diálogo, no momento mesmo em que o termo letramento entra no nosso dicionário, nos nossos discursos e práticas. "As pressões sociais exigem, simultaneamente, das universidades ações imediatas de inclusão e pesquisa para se compreender as 'novas identidades"” (Marinho 2010: 69).

Finalmente, em situação escolar, é preciso considerar as reivindicações locais, participando de suas demandas, em consonância com as palavras de Street (2010: 49): "deixem-nos ajudar naquilo em que vocês querem ajuda". Da mesma forma, é importante, deslocar o aparentemente visível para as demandas que emergem nesses contextos (Silva 2014).

Em termos didático-pedagógicos, pesquisadores brasileiros têm articulado esse conceito ao de gênero discursivo.

Se a língua é adquirida a partir de 'enunciações concretas', e é a partir dessas enunciações que são construídos os valores e sentidos de uma comunidade, entendemos que é com essas enunciações que o ensino de línguas precisa lidar. Em outras palavras, é preciso que o ensino de línguas se proponha a trabalhar a língua por meio dos diferentes gêneros do discurso em que se realiza. (Andrighetti \& Schoffen 2012: 22-23)

Trata-se de uma concepção de língua(gem) como ação conjunta de participantes (Clark 2000) engajados em um trabalho interacional conjunto para um propósito social. Para Kleiman (2006: 25-26), "uma concepção de linguagem como interação entre sujeitos em sociedade (sociointeracionista) implica uma crença na capacidade dos sujeitos sociais de criar ou construir contextos (construcionista), de forma sempre renovada, inovadora." Assim, embora as tomadas de posições e a resposta ativa (Bakhtin/Volochinov 1990, 1992) sejam constitutivas da linguagem, há necessidade de conhecimento das práticas específicas das diferentes instituições, concretizadas ou atualizadas nos eventos de letramento mediados pelos gêneros discursivos. 
Todo enunciado se atualiza em forma de gêneros, isto é, "como tipos relativamente estáveis de enunciados" (Bakhtin 1992: 279), o que inclui desde os diálogos cotidianos até as enunciações da vida pública, institucional, artística, científica e filosófica. Os gêneros, para o autor, não são adquiridos em manuais, mas nos processos interativos, surgindo na esfera prosaica da linguagem por ser esta a esfera mais ampla das formas culturais, e é no interior das práticas culturais que outras esferas discursivas são experienciadas. Assim, corroboramos o posicionamento de Kleiman (2006: 33): "acreditamos que é a prática social que viabiliza a exploração do gênero, e não o contrário".

Por fim, gostaríamos ainda de ressaltar a contribuição de Lea e Street (2006), quando reconhecem a escrita acadêmica como prática social, dentro de um contexto institucional e disciplinar determinado, destacando a influência de fatores como poder e autoridade na produção textual dos alunos. Qualquer esclarecimento teria que analisar as expectativas de professores e alunos em torno da produção escrita, evidenciando que escrever não é apenas uma habilidade técnica, da superfície da competência linguística e da assimilação cultural, mas está no nível da epistemologia, da autoridade e da contestação.

Uma das implicações desse modelo, assim como também defendeu Kleiman (2006), é de que a escrita é aprendida por meio da participação intencional, e não da instrução. Consequentemente "o papel do professor seria proporcionar atividades para que os alunos participassem de eventos significativos de letramento, situados socialmente, e com objetivos sociais relevantes." (Lea \& Street 1998: 546).

\section{Dos caminhos que nos levaram ao Colégio: o Observatório da Educação}

É sob esse enquadramento que refletimos sobre as condições epistemológicas implicadas em um trabalho de formação de professores induzido por um importante programa de intervenção na educação: o Observatório da Educação, iniciativa de instrumentalização de gestão das políticas educacionais e de incentivo à formação da pósgraduação. 
O Programa Observatório da Educação é coordenado por cursos de pós-graduação (mestrado e doutorado). Lançado em 2006, trata-se de um programa de abrangência nacional, implementado pela Coordenação de Aperfeiçoamento de Pessoal de Nível Superior (Capes) e pelo Instituto Nacional de Estudos e Pesquisas Educacionais Anísio Teixeira (INEP), órgãos vinculados ao Ministério da Educação do Brasil (MEC), operacionalizado localmente. Esse programa parte da pressuposição do ideal de transferência de um conhecimento universalizável e de habilidades cognitivas para aprendizagem descontextualizados -a serem testados por meio de exames internacionais e nacionais- ordenados pelo eixo da busca de resultados. As normas do programa exigem a utilização de dados educacionais produzidos pelo INEP como subsídio ao aprofundamento de estudos sobre a realidade educacional brasileira ${ }^{2}$ :

[...] a iniciativa apoia projetos de pesquisa que usem como base os bancos de dados do Inep, entre eles o Censo Escolar e o Sistema de Avaliação da Educação Básica (Saeb), entre outros. A intenção é estimular estudos sobre temas como a avaliação educacional, fluxo escolar, educação e mercado de trabalho, financiamento da educação e educação e demografia, para estimular a formação de mestres e doutores que atuem nas áreas de gestão de políticas educacionais, avaliação educacional e formação de professores (Ministério da Educação). ${ }^{3}$

Tais dados estatísticos comparam o Brasil a outros países. "Os resultados de diversos mecanismos de avaliação institucional como, por exemplo, o Programa Internacional de Avaliação de Alunos (PISA) e a Prova Brasil têm comprovado os baixos índices de aproveitamento escolar dos alunos nas escolas públicas brasileiras" (Pires-Santos 2012) e, de acordo o Índice de Desenvolvimento da Educação Básica $(\mathrm{IDEB})^{4}$, o País tem ficado muito aquém daquele atingido pelos países

2. Informação disponível em site do Ministério da Educação - MEC: http://observatorio. inep.gov.br/o-que-e. Acesso em: 17 set. 2013.

3. Disponível em: http://portal.mec.gov.br/index.php/?id=12309\&option=com content\&view=article. Acesso em 25 fev. 2014.

4. O IDEB é um indicador de qualidade educacional que combina informações de desempenho em exames padronizados (Prova Brasil ou Saeb) - obtido pelos estudantes ao final das etapas de ensino (4. ${ }^{\mathrm{a}}$ e $8 .^{\mathrm{a}}$ séries do ensino fundamental e 3 . $^{\mathrm{a}}$ série do ensino médio) - com informações sobre rendimento escolar (aprovação). A média nacional do IDEB, registrada em 2009 para os anos finais $\left(6 .^{\circ}\right.$ ao $9 .^{\circ}$ ano) do ensino fundamental, 
da Organização para a Cooperação e Desenvolvimento Econômico (OCDE).

No Colégio onde foi desenvolvido o Programa do Observatório da Educação, os indicadores observados pelo IDEB, das séries finais do Ensino Fundamental foram 3,4 em 2009, repetindo o mesmo resultado em 2011, e 3,7 em 201355. Como se observa, neste período houve um aumento pequeno no índice de avaliação, razão inicial da nossa presença lá, embora nossa experiência tenha ido muito além desse objetivo.

A finalidade do Observatório da Educação é clara. É tanto uma forma de instrumentalizar a gestão de políticas educacionais em busca da melhoria dos baixos índices dos níveis iniciais da educação, quanto projeto de fomento ao desenvolvimento de estudos e pesquisas em educação, de produção acadêmica, de formação de recursos pósgraduados em educação, em nível de mestrado e doutorado (docentes, gestores, avaliadores). Suas diretrizes tomam a educação como uma realidade inconteste, passível de ser "fortalecida", "ampliada" e "desenvolvida", visando um sistema de ensino eficiente para seus padrões de avaliação ${ }^{6}$.

O Programa Observatório da Educação é, portanto, conduzido por esses índices de avaliação educacional -nos termos de Street (2014), trata-se da governança global da educação, identificada pela OCDE e pelo PISA, coordenado em nível nacional pelo MEC e pela Capes e operacionalizado por pesquisadores localmente. Foi por meio desse Programa que iniciamos nossas atividades no Colégio.

De imediato, as próprias razões que nos induziram à entrada no Colégio para a formação de professores poderiam ser vistas como um

cresceu de 4,0 para 4,1 em 2011 e 4,2 em 2013. (Disponível em: http://portal.inep.gov. br/. Acesso em 22 set. 2014)

5. Disponível em: http://ideb.inep.gov.br/resultado/. Acesso em 03 nov. 2014.

6. O Observatório da Educação insere-se nas políticas públicas vigentes na década de 1990 e definidos na primeira década do século XXI. Uma de suas características é a afirmação de "parcerias" do público e privado, penetrando, de forma ampla, nas instituições educativas públicas e abrangendo desde propostas para o conteúdo do conhecimento até os métodos para sua produção ou socialização. Paralelamente, a ênfase na avaliação da educação para o decênio 2011-2020 do Plano Nacional de Educação induz as administrações estaduais e municipais a atentarem para esses parâmetros, descentralizando as ações, das quais a nossa é uma delas. 
obstáculo epistemológico à construção intersubjetiva de saberes, pois o objeto em questão - a relação entre fracasso escolar como um dado e o letramento escolar como uma solução esperada - expressava não só concepções, mas demandas divergentes. Articulava grupos sociais diferentes: por um lado, planejadores e gestores das instituições governamentais de educação, pesquisadores e estudantes também gestores de políticas públicas da universidade, e, por outro, professores, alunos e funcionários da escola onde o Programa Observatório da Educação seria desenvolvido. Obviamente tal entrelaçamento de pontos de vistas divergentes é próprio da imposição de temas e problemas feita por programas como o que está sendo descrito, condição que parecia, de antemão, impedir qualquer experiência etnográfica que nos inserisse nas práticas cotidianas da escola. Contudo, se essa imposição pode ser associada de forma imediata ao Programa Observatório da Educação, ela só teve legitimidade porque a educação é também vista como um problema, de forma quase indiscutível, para vários setores sociais. Nas percepções do senso comum, a educação é vista como uma necessidade para promover a ascensão social; nas divulgações midiáticas e nos discursos de políticos, a educação é valorizada para afirmar qualidades civilizadoras e libertadoras; nos programas governamentais, a educação é uma forma de instrumentalização para inserção no mercado de trabalho; nas produções acadêmicas, a educação é objeto de debates teóricos internos nos contextos contemporâneos; e, finalmente, nas percepções dos professores, a educação é parte das inquietações sobre os fins últimos da escola e sobre os melhores métodos para aprendizagem frente a tantos novos apelos aos jovens, como a TV, a internet, os jogos eletrônicos.

Bourdieu, Chamboredon e Passeron (1999) definiriam essa divergência de opiniões sobre a educação como uma imposição da problemática: todos estamos de acordo com o que discutir, mas o fazemos por razões e de modos diferentes. Diante disso, como pensar em produção do conhecimento em LA em sua dimensão intersubjetiva, entre professores e funcionários no Colégio, considerando essa imposição trazida por nossa inscrição no Programa e por todas as implicações decorrentes dela?

Se as pressuposições epistemológicas para a produção de conhecimento em LA supõem a apreensão de fenômenos ou eventos com- 
partilhados em que todos são participantes, como isso seria possível entre professores e alunos no cotidiano da escola se nossa presença, por si só, era a evidência inquestionável de relações assimétricas, identificadas na nossa posição como professores da universidade? Naquele momento inicial, éramos gestores de programas governamentais, "de fora", pesquisadores universitários com "muita teoria, mas distantes da prática de sala de aula".

\section{3. "Ver o que não se enxergava": condições epistemológicas para o conhecimento compartilhado em contexto}

É esse desafio que passamos agora a descrever, apresentando o processo pelo qual as condições epistemológicas para a produção de conhecimento em contexto se tornaram possíveis. Como se sabe, em todo processo de produção de conhecimento coletivo ocorrem certos eventos, ou decisões, que podem inesperadamente alterar o rumo da pesquisa. No nosso caso, a regularidade de um grupo de estudos e de discussão fez com que nos tornássemos mais próximos uns dos outros e, com isso, houvesse tempo e espaço para ouvir e atender às propostas de trabalho conjunto. E foi o que aconteceu com a proposição feita pelos professores, depois de uma discussão no grupo de desenvolver um projeto para o conhecimento da história do bairro, que passou a ser denominado Projeto Memória. Esse foi um momento de inflexão decisivo, com resultados estimulantes do ponto de vista do ensino e da aprendizagem em contexto, do conhecimento compartilhado e da convivência diária entre nós. Assim, é importante descrever como chegamos a esse momento, que envolveu, além dos professores, alunos, moradores do bairro, estagiários da graduação em Letras e funcionários da escola.

Os primeiros passos para a nossa aproximação com os professores do Colégio foi encaminhar o Programa do Observatório da Educação ${ }^{7}$, antes mesmo de ser enviado à Capes para concorrer ao Edital, ao Nú- 
cleo Regional de Ensino da Secretaria Estadual de Educação (SEED), para ser analisado e autorizado pela equipe de ensino do Núcleo, órgão máximo de regulação da educação no município. Em seguida, em um encontro com a diretora do Colégio, expusemos o Programa, quando deixamos uma cópia para análise e solicitamos uma conversa com todos os professores, para apresentação e busca de adesão. É importante lembrar que, de acordo com o edital, a anuência quanto à participação no Programa por parte de toda a equipe - tanto dos professores da Unioeste como os do Colégio - deveria ser assinada por todos e encaminhada à Capes.

O Programa tinha seis (6) bolsas disponíveis para professores, cinco (5) bolsas para alunos da graduação, uma (1) bolsa para mestrado, uma (1) bolsa para doutorado e uma (1) bolsa para a coordenação. As bolsas destinadas aos professores do colégio foram distribuídas entre professores de diferentes áreas de conhecimento, para que pudéssemos organizar um projeto interdisciplinar, e com prioridade àqueles há mais tempo no Colégio, com vínculos mais consistentes com o mesmo e com os alunos, já que havia uma grande rotatividade de professores. Além dos bolsistas, os outros participaram do Programa como voluntários. Durante o desenvolvimento houve alternância entre os participantes voluntários, embora alguns tenham permanecido durante toda a duração do Programa. Manteve-se uma média de 25 participantes durante os 36 meses, entre 06 professores bolsistas, 03 de Língua Portuguesa, 01 de Geografia, 01 de Matemática e 01 de Ciências; 05 alunas bolsistas e 01 voluntária dos cursos de Letras Português/Inglês e Português/ Espanhol da Unioeste, as quais desenvolveram seus estágios curriculares supervisionados juntamente com os professores do Colégio; 04 professoras da Unioeste, duas delas do Mestrado Interdisciplinar em Sociedade, Cultura e Fronteiras; 01 orientadora educacional e demais professores, de diferentes áreas, do Colégio.

Buscando facilitar nosso primeiro encontro com todos os professores - o Colégio funciona em três turnos, o que dificultaria a exposição a todos - a diretora nos convidou para participar do encontro pedagógico da escola, atividade obrigatória, com data estabelecida de acordo com o calendário das escolas estaduais, no início do ano letivo. Durante o encontro, fizemos a exposição do Programa visando à formação dos professores, e nos colocamos na escuta para esclarecimentos e expli- 
cações. Um dos primeiros comentários que nos chamou a atenção, conforme palavras do professor de Geografia, Mauro ${ }^{8}$, e confirmado por vários outros, foi "são tantos os projetos propostos para a escola que não temos mais tempo de dar aulas" (anotação em diário de campo).

Esse comentário incide diretamente nas discussões do letramento feitas pela Linguística Aplicada, que pretende justamente desfazer, no próprio processo de formação, o grande abismo entre as práticas do cotidiano escolar e as pesquisas realizadas na Universidade, também percebido por professores da educação básica. Outra possível explicação para essa reação pode estar relacionada à desqualificação por que passa o trabalho dos professores, reiterada pelos diferentes mecanismos de avaliação nacional e internacional presentes em diversos projetos desenvolvidos nessa escola. A interferência externa pode ser vista não como uma forma de cooperação para um trabalho conjunto, mas como uma ameaça, pela imposição de um conhecimento considerado superior e, consequentemente, também uma desqualificação do trabalho ali construído. Mas, o comentário do professor também revela, literalmente, o número crescente de projetos propostos por diferentes instituições públicas e privados, desde universidades e órgãos públicos de fomento até bancos. Nesse encontro com os professores, embora tivéssemos apresentando um Programa voltado para formação de professores já delineado, insistimos em que todas as ações seriam propostas e desenvolvidas conjuntamente, de acordo com os interesses e necessidades dos alunos e professores do Colégio.

Na primeira reunião realizada pelo Programa no Colégio, organizamos o grupo de estudo sobre leitura, escrita e oralidade, temáticas que consideramos fulcrais para todas as áreas do conhecimento e forma de construção da interdisciplinaridade, pois todos somos em primeiro lugar, indiscutivelmente, professores de leitura, escrita e oralidade. Para não interferirmos no andamento das atividades escolares, a opção foi realizar o grupo de estudo aos sábados, uma vez por mês, das $08 \mathrm{~h}$ às $12 \mathrm{~h}$. Essa solução não era a ideal, pois o professor, altamente sobrecarregado com um número exaustivo de aulas, também se via privado de um tempo precioso para o descanso e para a convivência familiar.

8. Por questões de ética, os participantes da pesquisa serão apresentados por meio de pseudônimos. 
Contudo, foi aceita por todos, evidenciando o empenho do professor com sua atividade e com o aprendizado do aluno e, consequentemente, com a melhoria da educação, contrariamente ao que vem sendo amplamente divulgado pela mídia quanto à falta de interesse do professor. Essa foi, para nós, uma das primeiras rupturas com essa percepção comum a respeito dos professores, fundamental e um motivo de admiração, pois eram comuns no colégio atividades desse tipo aos sábados, sem remuneração.

A dinâmica para o funcionamento do grupo de estudo foi a organização de temas a serem estudados, de acordo com seleção dos textos a serem antecipadamente lidos, observando as sugestões de todos: professores do Colégio, estagiários da graduação e nós. A cada encontro se definia, prévia e voluntariamente, quem conduziria as discussões durante o estudo, havendo sempre o cuidado de alternar essa participação. Foi curioso perceber o receio dos professores do Colégio em se oferecerem voluntariamente, no início. Então aguardamos os três primeiros encontros para que todos se familiarizassem com essa dinâmica. Como a resistência persistiu, sugerimos que as acadêmicas se voluntariassem, o que desfez os receios iniciais quanto à capacidade ou não de orientar as discussões. Essa dinâmica do grupo de estudo contribuiu para romper com as relações assimétricas entre pesquisadores da universidade, professores do Colégio e estagiários da graduação, tornando possível a todos nós nos percebermos como pares, minimizando o distanciamento inicial.

A dinâmica do grupo de estudos, mesmo ancorada em textos teóricos -cujos temas eram a escrita como um trabalho (Garcez 2004; Fiad \& Mayrink-Sabinson 1991), as relações interdisciplinares entre leitura, escrita e oralidade (Kleiman \& Moraes 2007), a construção de pedagogias culturalmente relevantes (Osborne 1996; Gandin, Diniz-Pereira \& Hypolito 2002; Bortoni-Ricardo \& Dettoni 2003), gêneros discursivos enquanto prática social (Baccin 2000; Marcuschi 2002; Dolz, Noverraz \& Schneuwly 2007), a mudança de paradigmas contemporâneos (Sousa Santos 1988) - estimulou um processo de reflexividade pautado nas práticas cotidianas de sala de aula, permitindo visualizar limites e alternativas por um reconhecimento de experiências compartilhadas. Por meio desses encontros de estudo - que se estenderam por dois anos - e após 12 meses, discutimos conjuntamente a ideia de um projeto coletivo e interdisciplinar a ser desenvolvido em sala de aula. Depois 
de várias sugestões, os professores propuseram desenvolver um projeto que reconstruísse a memória do bairro, que ficaria sob a coordenação de um deles no Colégio. Esse tema foi escolhido para a preparação da Semana de Interação Comunidade e Escola que seria realizada no segundo semestre de 2012. A proposição dessa temática foi ainda, segundo os professores, um meio de demover as percepções de uma forte estigmatização negativa do bairro e, em decorrência, também da escola, por parte dos moradores da cidade, mas também de alguns professores e alunos da própria escola. Deste modo, reconstruir a história do bairro e do Colégio, além de devolver a imagem do bairro para si mesmo, possibilitaria a percepção de todos como atores ativos dessa história. Embora o bairro e a escola sejam inseparáveis, sair literalmente de seus muros físicos para ir ao encontro dos moradores era uma necessidade, também porque havia uma percepção imediata, por parte dos professores da escola, de que os pais dificilmente participavam da vida escolar de seus filhos, conforme consta no Projeto Político Pedagógico da Escola. Alunos e professores poderiam aprofundar o diálogo fazendo o caminho inverso, ouvindo os protagonistas da história do bairro.

E esse foi o ponto de inflexão decisivo, tornando as atividades de formação de professores do Programa não só coletivas, mas abrindo possibilidades para a construção de um conhecimento contextualizado que não distanciou o letramento escolar do bairro onde ele ocorre. Foi decisivo porque desencadeou várias atividades para a construção compartilhada de um conhecimento local, um trabalho colaborativo que identificamos como fundamentalmente etnográfico. Embora nossa proposta inicial não tenha sido fazer uma etnografia, focalizar o letramento como prática social para a formação de professores propiciou esse encaminhamento inerente à nossa participação no Colégio. Além disso, a formação acadêmica em Antropologia e Linguística Aplicada dos proponentes locais do Programa resultou inevitavelmente em uma inserção etnográfica.

\section{Projeto Memória: a materialização do conhecimento compartilhado}

O Projeto Memória, como passou a ser denominado, foi então mais do que uma reconstrução da história do bairro. Tornou-se uma forma de participação em práticas sociais entre os moradores e, ao mesmo 
tempo, um eixo em torno do qual convergiram diversas atividades de leitura, de escrita e de oralidade. Assim, foram selecionados gêneros discursivos significativos de práticas sociais locais, que contribuíram, por essa razão, com a realização do projeto, propiciando, de forma interdisciplinar, uma interlocução entre todos os participantes: pesquisadores, alunos da escola, professores, moradores e estagiários, todos enredados em uma dimensão dialógica e reflexiva no trabalho coletivo, em que nos víamos todos como construtores.

Do ponto de vista das abordagens analíticas da Linguística Aplicada, o Projeto Memória permitiu compreender, na prática cotidiana do Colégio, que a leitura, a escrita e a oralidade não podem ser vistas fora do contexto social em que os eventos de letramento ocorrem sendo, por isso, também consideradas como práticas sociais específicas (Garcez 2004; Kleiman \& Moraes 2007; Koch \& Elias 2007, entre outros), ou práticas de letramento (Street 2010), pois todos os gêneros discursivos deixaram de ser vistos como conceitos abstratos, ao estarem imersos nos processos interativos da experiência coletiva do bairro e da história de cada um (Lave 1988, 1991, 1996; Toren 1993).

Deste modo, foi atentando às experiências vivenciais dos alunos para além da escola e buscando o que nos unia a eles, em suas diferenças linguístico-culturais, que os gêneros discursivos se revelaram como práticas sociais compartilhadas entre nós, em diferentes graus tanto de familiaridade quanto de estranhamento. Por meio deles foi possível trabalhar as práticas sociais de uso da leitura e escrita enquanto práticas do cotidiano, pois, para reconstruir a memória do bairro, foram utilizados carta-convite para os moradores do bairro participarem de entrevistas e da semana interativa, carta de agradecimento para aqueles que participaram, realização de entrevistas, produção de biografia e de autobiografia, "causos", receitas culinárias, literatura de cordel e peça teatral.

Esses gêneros trouxeram para o centro, e em primeiro plano, as tensões entre o letramento escolar e os saberes locais na prática cotidiana do professor, observadas claramente na seguinte reflexão da professora de Língua Portuguesa, Maria.

Ele [o professor] dentro de um contexto em que está trabalhando o conteúdo, quando é que ele vai se preocupar em trabalhar essa lista de 
Maria E. Pires-Santos, Mariangela G. Lunardelli, Neiva M. Jung, Regina C. Machado e Silva

conteúdos? Ele acha que a Secretaria da Educação vai mandar essa lista para que ele possa utilizar. Na verdade, o trabalho com a pesquisa, a gente trabalha com a essência do aluno, o que o aluno traz. Não tem como vocêficar repetindo, é uma coisa que vai surgir, na pesquisa, no próprio trabalho da pesquisa, vão surgindo as necessidades a serem trabalhadas. Porque não é uma coisa pronta, porque o desenvolvimento do nosso projeto vai ter coisa que a gente vai falar: cadê nossa lista? Mas não tem essa lista, porque a gente está trabalhando com pesquisa, e essa pesquisa é a busca do conhecer, de construir juntos, né! (Fala da Professora Maria. Gravação em áudio).

A reflexão da professora transcrita acima expõe de forma clara as tensões vividas entre as vivências experienciadas a partir do projeto e as orientações de trabalho das Diretrizes Curriculares de Língua Portuguesa do Estado do Paraná, que pré-determina uma lista de conteúdos a serem abordados em cada série, independente do contexto da escola, isto é, tendendo a desconsiderar os saberes particulares dos alunos como fundamento legítimo para aprendizagens situadas. O confronto resultante não é simples de ser resolvido, mas pode ser enfrentado pela professora em sala de aula em função da participação dela em um trabalho coletivo em que havia uma finalidade clara: o Projeto Memória.

Tais tensões entre o letramento escolar e os saberes locais foram atualizadas em diferentes situações de utilização dos gêneros em práticas reais de uso da linguagem. Contudo, embora tenhamos registros de todos os gêneros que surgiram dessa experiência de formação, aqui serão abordadas apenas a entrevista, a receita culinária e a peça teatral.

O gênero discursivo "entrevista" surgiu da necessidade de os alunos entrevistarem os antigos moradores do bairro, para conhecerem suas histórias. Para isto, foram trabalhadas as dimensões do gênero, a forma composicional, suas funções sociocomunicativas, a postura ética que se espera adotar para a realização das entrevistas. Antes de realizarem as entrevistas, os alunos leram números antigos do jornal do bairro, que traziam histórias da sua construção. Fizeram também um inventário das lojas comerciais, das igrejas, dos locais de lazer e de serviços como a reciclagem do lixo, etc., bem como procuraram 
conversar com outros jovens sobre o que faziam em seus momentos de lazer. O reconhecimento do gênero discursivo entrevista foi orientado por professores e estagiários e, depois, elaboradas as perguntas a serem feitas aos moradores. A professora de Matemática elaborou, juntamente com os alunos, gráficos com dados estatísticos do nível de renda dos moradores, das atividades de lazer a que se dedicam, dos serviços de saúde e outros serviços. As entrevistas, realizadas pelos alunos e gravadas em vídeo, ocorreram em duas etapas, em uma chácara localizada no bairro e distante da escola quase 1000 metros, utilizada pelos moradores para momentos de lazer. Todos nós participamos desses momentos. A entrevista realizada na segunda etapa, que reuniu maior número de alunos e de professores da escola, começou com a caminhada do Colégio até a chácara, e revelou-se um evento festivo, mas também simbólico da interação significativa entre o Colégio e o bairro (Silva 2013).

É interessante evidenciar o protagonismo dos professores no encaminhamento desse trabalho. Ainda utilizando o gênero entrevista, as professoras de Espanhol, de Inglês e de Matemática realizaram um trabalho interdisciplinar. A professora Joana, de Espanhol, articulou a entrevista ao contexto migratório da fronteira, legitimando esse contexto e a língua espanhola falada na fronteira:

Eu li alguns trechos pra explicar como funciona a entrevista, mas ainda é tão recente, mas a primeira entrevista já saiu, mas eles ainda fizeram pergunta e resposta. Eles não conseguem conduzir porque eles ainda não têm conhecimento desse gênero, tem que ser melhor trabalhado. Ai nós conseguimos então, como eu trabalho com língua espanhola eu pedi a eles que procurassem pessoas descendentes de hispanohablantes que fossem filhos de paraguaios mesmo ou brasiguaios. Duas alunas que são filhas de brasiguaios já se disponibilizaram para entrevistar um senhor que vive na frente da casa delas. Ai nós acompanhamos elas quinta-feira passada, conversamos com o menino e ele concedeu a entrevista. Nós gravamos, e ele contou. Mesmo sendo perguntas e respostas, ainda não é uma narrativa. Por que ele veio parar aqui no bairro, o que chamou a atenção, ele saiu lá de San Alberto no Paraguai e veio pra cá por quê? (Fala da professora no grupo de estudo, maio/2012)

Como se pode observar o gênero discursivo deixou de ser apenas uma unidade de ensino, mas encarnou o vínculo do ensino dessa 
professora com a vivência do bairro, marcado pela dinâmica das idas e vindas de pessoas transfronteiriças. Essa percepção evidencia a importância de se partir de uma prática social para a composição dos gêneros de acordo com as necessidades sociocomunicativas locais, como discute Kleiman (2006), e como passou a ser reconhecido pelos participantes do projeto.

O trabalho com o gênero discursivo "receita culinária" teve como finalidade fazer um levantamento das receitas mais utilizadas nas casas dos alunos. Esse trabalho foi desenvolvido pela professora de Português, de Artes, de Matemática e uma estagiária. Entre as receitas, aquela que se mostrou mais apreciada e feita nas casas dos alunos foi o bolo de chocolate. A receita foi escolhida como a 'Especialidade da Casa' do bairro para ser elaborada por alunos e professores. Nas palavras da professora de Matemática Lúcia, "um dos momentos mais especiais foi quando o bolo estava pronto para a degustação, e isso me fez lembrar o que diz Rossini (2003) 'a criança aprende efetivamente quando relaciona o que aprende com seus próprios interesses"” (anotação em diário de campo). Durante a preparação do bolo, a professora de Matemática trabalhou com as medidas (de massa, volume, temperatura) e frações, e a professora de Artes orientou a confecção das capas dos cadernos de receita.

O gênero discursivo "peça do teatro" foi proposto por uma professora, há 11 anos na escola, que se responsabilizou pela encenação de uma peça de teatro que contasse a história do bairro e fosse perfomatizada pelos alunos dos oitavos anos. A elaboração da peça de teatro teve também a colaboração de uma estagiária, que fez um estudo mais profundo das técnicas utilizadas; além disso, auxiliou na montagem do texto e nos ensaios. A escrita do texto dramático foi feita conjuntamente. Nele a história foi relembrada com cuidado e com carinho, trazendo em primeiro plano as várias reuniões entre moradores e dos moradores com representantes do poder público municipal na luta pela infraestrutura adequada para o bairro e para a construção do Colégio. Foi a encenação da busca de um sonho - a casa própria - e de uma trajetória marcada pela luta política, desconhecida até então pelos jovens e crianças do Colégio.

À medida que trabalhavam com a parte técnica, os alunos foram ficando mais à vontade em trabalhar esse gênero, compreenderam bem 
os elementos necessários para a encenação de uma peça e, logo após este estudo, a professora, estagiária e alunos começaram a escrita do texto. Para a escrita, todos os dados trazidos sobre o bairro junto aos moradores, por meio dos demais gêneros, foram utilizados.

Durante a escrita, a professora utilizou uma linguagem mais formal, mas um dos alunos fez o seguinte comentário:

Professora, os moradores daqui não falam assim não, eles não tiveram escolaridade; nós, os filhos, que estamos estudando, é que usamos mais concordâncias e uma linguagem mais formal; logo, temos que representar a voz do povo do Bairro Conquista e essa voz do texto não pertence a eles. (Fala de Mariano, aluno do $8 .^{\circ}$ ano, em sala de aula. (anotação em diário de campo, junho/2012)

De intervenções reflexivas e de participações como essas, o texto foi modificado várias vezes, o que rendeu noites de reescritas de texto, discussões divertidas e resultaram na apresentação da peça, encenada nos três turnos - matutino, vespertino e noturno - na Semana Interativa Comunidade Escola, do dia 28 de agosto de 2012, encerrado com o seguinte poema escrito pela professora:

Em cada consciência, uma lembrança.

Bairro Conquista, um sonho, uma esperança, uma nova chance...

A hora não é de sofrer, não deixa a tristeza saber.

A vida ensina, a escola da vida foi assim.

Sonhos não envelhecem.

Homens que aqui ocuparam se resumiam em sonhos.

O sonho da casa própria!

Um passo atrás do outro, um tijolo que se erguia, uma mão amiga

Uma gente querida, numa nova vila, vida, paisagem.

Bairro Conquista, memória viva hoje e sempre! (Patrícia de Souza)

Tal apropriação contextualizada desses gêneros como meio de obter dados para a pesquisa de reconstrução da memória do bairro permitiu o reconhecimento de todos - professores, alunos, pesquisadores, estagiários - interagindo em processo tanto coletivo quanto histórico. Esse reconhecimento e ressignificação da história do bairro ficam evidentes nos versos a seguir dos alunos dos sextos anos em um livro que organizaram em forma de Literatura de Cordel. 
Maria E. Pires-Santos, Mariangela G. Lunardelli, Neiva M. Jung, Regina C. Machado e Silva

O prefeito ofertava

Outro lugar para morar

O povo não gostava

Negociou-se, até um bom lugar encontrar. (Elen, $6 .^{\circ} \mathrm{A}-11$ anos)

Escola, no bairro não tinha

Estudar, só na escola vizinha

"Pé sujo" era o nosso apelido, por causa da poeira,

Pois o bairro era muita sujeira. (Carla, $6 .^{\circ} \mathrm{A}-11$ anos)

Assim, emergiu o inventário da história do bairro e do Colégio. A construção do bairro teve início em 1998, espaço para assentamento dos moradores retirados das margens do rio Paraná onde seria construída uma avenida. Só em 1999 os primeiros moradores tomaram posse de suas casas, depois de muitas reivindicações, exigindo da Prefeitura Municipal as mínimas condições de infraestrutura urbana. O Colégio também foi fruto de uma conquista para atender à necessidade de escola no bairro e, assim, em 2002 passou a funcionar.

Para além da reconstrução da história do bairro e da escola por meio dos gêneros, como descrevemos acima, alunos e professores recolheram documentos, artigos de jornais, fotos que registraram diferentes momentos da história do bairro e da construção do Colégio, junto aos moradores. Trouxeram fotos antigas, retratando o terreno vazio, onde posteriormente seriam construídas as casas e o Colégio. Fizeram um levantamento dos moradores mais antigos e também daqueles que tiveram um papel de liderança quanto às reivindicações por melhorias no bairro, bem como identificaram os músicos e poetas, para serem posteriormente entrevistados. Acompanhados de professores, percorreram as ruas do bairro, para registrar, em fotos, o momento atual. Os próprios alunos se surpreenderam com lugares que não conheciam, embora o bairro seja relativamente pequeno e recente. Nesse reconhecimento, encontraram um jornal em funcionamento, uma biblioteca pública organizada e mantida por voluntários do próprio bairro, da qual fazem parte alguns alunos da escola, e que cederam documentos digitais de sua autoria. Todos os registros do Projeto Memória como gravações orais, vídeos, documentos como jornais, documentos institucionais, fotografias e produções orais, escritas e visuais dos alunos estão arquivados no Colégio, compondo elementos para reflexões sistematizadas, 
apresentadas por professores do Colégio e estagiários em seminários da universidade, no Núcleo Regional de Educação de Foz do Iguaçu e em outros colégios, inclusive de cidades próximas.

A cada etapa da pesquisa realizada por alunos e professores da escola, os resultados eram partilhados entre alunos, professores da escola, estagiárias, pesquisadores e bolsistas participantes do Observatório da Educação, com a utilização da TV Pendrive ${ }^{9}$ ou multimídia. Nesses momentos, os alunos identificavam suas casas, as casas dos seus colegas, o comércio, as igrejas, as escolas, a creche, o posto de saúde (Postinho), a pastoral da criança (local onde muitos estudam ou estudaram catequese), o clube esportivo, a casinha sobre a árvore de que eles tanto gostam. O aluno Tiago do $8 .^{\circ}$ ano perguntou "como conseguimos fazer tudo ficar tão bonito?". A professora comentou que, provavelmente, eles estavam começando a "ver" o que não "enxergavam", como participantes imersos no cotidiano do bairro.

\section{Considerações finais}

Esta formulação - ver o que não se enxergava - talvez sintetize com clareza o processo pelo qual é possível argumentar em favor dessa epistemologia da pesquisa no campo da Linguística Aplicada, por ter propiciado um conhecimento que, partindo da prática cotidiana escolar, possibilitou reflexões teórico-metodológicas. Por sua vez, essas reflexões reverteram em novas práticas de letramento para fomentar o surgimento de outras demandas e outras reflexões que geraram a busca de outras práticas. Tal movimento, como os professores comentavam, uma vez iniciado, dificilmente permite retorno e/ou acomodação justamente pelo envolvimento comprometido da comunidade escolar e o processo de interlocução de três anos entre todos os agentes vinculados ao Programa Observatório da Educação (professores, estagiários,

9. TV Pendrive é um projeto da Secretaria de Educação do Estado do Paraná, por meio do qual o estado instalou um televisor de cor laranja nas salas de aula, com entrada para cartão de memória. O objetivo desse projeto é proporcionar aos professores recursos que podem complementar e apoiar o processo de ensino-aprendizagem. Eles poderiam salvar, em seu pendrive, objetos de aprendizagem disponíveis no Portal Dia-a-dia Educação do Estado do Paraná e utilizá-los nas aulas. (Disponível em: http://www.gestaoescolar.diaadia. pr.gov.br. Acesso em: 21 out 2014). 
bolsistas da graduação e da pós-graduação, professores do Colégio, diretora, alunos, bibliotecários e moradores do bairro).

Considerando que a preocupação central da Linguística Aplicada é com o uso situado da linguagem, pelo sujeito social em sua heterogeneidade, uma epistemologia do conhecimento supõe as condições imanentes ao próprio contexto da experiência vivida. Isto é, a proposição feita pelos professores de construir a memória do bairro e do Colégio foi um ponto de convergência para o qual os processos interativos locais se atualizaram em práticas letradas locais e escolares. Como se pode observar, os gêneros discursivos foram expressão de enunciados concretos, situados sócio-historicamente no tempo-espaço do bairro e do Colégio, falados e escritos por interlocutores reais. Todo o processo, para além dos gêneros discursivos, evidenciou o entrelaçamento inseparável da vida do bairro e da vida escolar, realçando inclusive a dimensão estética da vida ali vivida. Tal entrelaçamento produziu as condições efetivas para a construção de um conhecimento coletivo: reflexivo, em termos das práticas de letramento locais; crítico, em torno do reconhecimento recíproco dos envolvidos em relação à participação política do bairro frente à cidade, afirmando o papel ativo na própria história; dialógico, tanto em relação aos saberes compartilhados quanto ao amplo processo de interlocução entre a comunidade escolar e do bairro.

Uma das considerações que não poderia deixar de ser feita é sobre as condições do nosso trabalho como professores e pesquisadores universitários, demandados por programas vinculados a políticas públicas, neste caso, voltadas para a Educação Básica. Como evidenciamos, mesmo atendendo às políticas da governança global da educação, como a Prova Brasil - o que a princípio seria uma intromissão assimétrica e um obstáculo epistemológico à produção do conhecimento em LA - a orientação teórico-metodológica e a frequentação contínua e de longa duração permitiram a construção intersubjetiva de saberes locais.

Finalmente, tal como a LA concebe, se a linguagem como prática social também é expressiva das lutas e das diferenças entre grupos sociais, foi por meio dela que se articularam as demandas desses grupos com interesses dissonantes. Planejadores e gestores das instituições governamentais de educação, pesquisadores e estudantes também gestores de políticas públicas da universidade, moradores do bairro, 
professores, alunos e funcionários do Colégio onde o Programa Observatório foi desenvolvido fizeram com que emergissem não só os interesses e as diferenças dos grupos sociais do bairro em relação à cidade, mas sobretudo o próprio reconhecimento desses atores como coconstrutores de saberes e de práticas de um letramento próprio que excede o letramento escolar. Como diz o personagem de Gabriel García Márquez, José Arcádio Buendía, "aqui não tem nada para ser corrigido" (2014: 98).

Recebido em outubro de 2014 Aprovado em outubro de 2014 E-mails: mepires@gmail.com; mglunardelli@gmail.com; neivajung@yahoo.com.br; coeli.machado@yahoo.com.br

\section{Referências bibliográficas}

Andrighetti, Graziela H. \& Schoffen, Juliana R. 2012. Vivenciando língua e cultura: sugestões para práticas pedagógicas em Português como Língua Adicional. In: Juliana R. Schoffen et. al. Orgs. Português como Lingua Adicional: reflexões para a prática docente. Porto Alegre: Bem Brasil. p. 17-44.

Baccin, Edena J. 2000. Modelo Didático de Gênero e Sequência Didática: Gênero Textual Autobiografia. Disponível em: http://www. diaadiaeducacao.pr.gov.br/portals/pde/arquivos/2000-6.pdf. Acesso em: 10 mai 2013.

Bakhtin, Mickail. 1990. Marxismo e filosofia da linguagem. São Paulo: Hucitec.

1992. Estética da criação verbal. São Paulo: Martins Fontes.

Barton, David, Hamilton, Mary \& Ivanic R (orgs.). 2000. Situated literacies: reading and writing in context. Londres e Nova York: Routledge.

Blommaert, Jan \& RAmpton, Ben. 2011. Language and Superdiversity. Diversities 13/2:1-21.

Bortoni-Ricardo, Stella M. \& Dettoni, Raquel V. 2003. Diversidades lingüísticas e desigualdades sociais: aplicando a pedagogia culturalmente sensível. Em: Maria Inês Cox \& Ana Assis-Peterson. Cenas de Sala de aula. Campinas: Mercado de Letras. p. 81-104. 
Bourdieu, Pierre; Chamboredon, Jean-Claude \& Passeron, Jean-Claude. 1999. A profissão de sociólogo. Preliminares epistemológicas. Petrópolis: Vozes.

Cavalcanti, Marilda C. 1986. A propósito da Linguística Aplicada. Trabalhos em Linguística Aplicada. 7:5-12.

Clark, Herbert H. 2000. O uso da linguagem. Cadernos de Tradução. Porto Alegre, n. 9:49-71.

Celani, Antonieta A. M. 1992. Afinal, o que é Linguística Aplicada? In: Mara S. Z. Paschoal \& Antonieta A. M. Celani. Orgs. Linguística Aplicada. Da aplicação da Linguística à Linguística Transdisciplinar. São Paulo: EDUC. p. 15-23.

Dolz, Joaquim; Noverraz, Marcel \& Schneuwly, Bernard 2007. Sequências didáticas para o oral e a escrita: apresentação de um procedimento. In: SCHNEUWLY, B.; DOLZ, J. e colaboradores. Gêneros orais e escritos na escola. Campinas: Mercado de Letras.

EuzÉBIO, Michelle D. 2011. Usos sociais da escrita na família e na escola: um estudo sobre prática e eventos de letramento em uma comunidade escolar em Florianópolis/SC. Florianópolis, SC. Dissertação (Programa de Pós-graduação em Linguística). Universidade Federal de Santa Catarina, Florianópolis.

Fiad, Raquel S. \& MaYrink-Sabinson, Maria L. T. 1991. A escrita como trabalho. In: M. H. Martins Org. Questões de linguagem. São Paulo: Contexto. p. 54-63.

Gandin, Luís A.; Diniz-Pereira, Júlio E.; Hypolito, Álvaro M. 2002. Para além de uma educação multicultural: teoria racial crítica, pedagogia culturalmente relevante e formação docente (entrevista com a professora Gloria Ladson-Billings). Educação e Sociedade, 23/79: 275-293. (disponível em: http://www.scielo.br/pdf/es/v23n79/10858. pdf. Acesso em: 14 out. 2012).

Garcez, Lucília H. C. 2004. Técnica de redação: o que é preciso saber para bem escrever. São Paulo: Martins Fontes.

Goody, Jack \& WATt, Ian. 2003. Las consequencias de la cultura escrita. In: Jack Goody Org. Cultura escrita em sociedades tradicionales. Trad. Gloria Vitale e Patricia Willson. Barcelona: gedisa editorial: 39-82.

Heath, Shirley B. 1983. Ways with words: language, life and work in communities and classrooms. Cambridge: Cambridge University Press.

2001. What no bedtime story means: narrative skills at home and school. In: Alessandro Duranti. Org. Linguistic Anthropology: a reader. Oxford: Blackwel. p. 318-342. 
JunG, Neiva M. 2009. A (re)produção de identidades sociais na comunidade e na escola. Ponta Grossa/PR: Editora da UEPG.

Kleiman, Angela B. (org.). 1995. Os significados do letramento: uma nova perspectiva sobre a prática social da escrita. Campinas, SP: Mercado de Letras.

.2006. Leitura e prática social no desenvolvimento de competências no ensino médio. In: Clécio Bunzen \& Márcia Mendonça. Orgs. Português no ensino médio e formação do professor. São Paulo: Parábola editorial. p. 23-36.

\& Moraes, S. E. 2007. Leitura e interdisciplinaridade. Campinas: Mercado de Letras.

2013. Agenda de pesquisa e ação em Linguística Aplicada: problematizações. In: Luiz P. Moita Lopes. Org. Linguística Aplicada na modernidade recente. São Paulo: Parábola. p. 39-58.

Kосн, Ingedore V. \& Elias, V. M. 2007. Ler e compreender: os sentidos do texto. São Paulo: contexto.

LAVE, Jean. 1988. Cognition in practice: mind, mathematics and culture in everyday life. Cambridge: Cambridge University Press.

. 1996. Teaching, as learning, in practice. Mind, Culture and Activity. 3/3. p. 149-164.

; Wenger, Etienne. 1991. Situated Learning. Cambridge: Cambridge University Press.

Lea, Mary, R. \& Street, Brian V. 1998. Student writing in higher education: an academic literacies approach. Studies in Higher Education, 23/2:157-172.

\& . 2006. The "Academic Literacies" Model: Theory and Applications. Theory into Practice Fall, 45/4: 368-377.

MarCuSCHI, Luiz. A. 2002. Gêneros textuais: definição e funcionalidade. In: Angela P. Dionisio; Anna R. Machado; Maria A. BEZERRA. Gêneros textuais \& ensino. Rio de Janeiro: Lucerna.

MARINHO, Marildes. 2010. Letramento: a criação de um neologismo e a construção de um conceito. In: Marildes Marinho; Gilcinei T Carvalho (Orgs.). Cultura escrita e letramento. Belo Horizonte: Editora UFMG. p. 68-100.

Márquez, Gabriel G. 2014. Cem anos de solidão. 82 ed. Rio de Janeiro: Record.

Morta Lopes, Luiz P. 1996. Afinal o que é Linguística Aplicada? In: Luiz P. Moita Lopes. Org. Oficina de Linguística Aplicada. Campinas/SP: Mercado de Letras. p. 17-26.

2009. Da aplicação de linguística à linguística aplicada indisciplinar. In: Regina C. Pereira \& Pilar Roca. Orgs. Linguística 
Aplicada: um caminho com diferentes acesos. São Paulo: Contexto. p. 1-24.

. 2013. Fotografias da Linguística Aplicada brasileira na modernidade recente: contextos escolares. In: Luiz P. Moita Lopes. Org. Linguística Aplicada na modernidade recente. São Paulo: Parábola. p. 15-38.

Osborne, A. Barry. 1996. Practice into theory into practice: culturally relevant pedagogy for students we have marginalized and normalized. Anthropology \& Education Quartely 27/3:285-314.

Peirano, Mariza. 1995. A favor da etnografia. Rio de Janeiro: Relume Dumará.

Pires-Santos, Maria E. 2012. Deslocamentos transfronteiriços e as narrativas de identidades. In: Regina C. M. Silva \& Maria E. PiresSantos. Orgs. Interdisciplinaridade e fronteiras: movimentos, identidades e configurações. Cascavel/PR: Unioeste. p. 147-173.

. 2011. Observatório da Educação - Núcleo de pesquisa/extensão: formação continuada em leitura, escrita e oralidade. Unioeste. Mimeo. RAMPTON, Ben. 2006. Language and Late Modernity. Interaction in an Urban School. Cambridge: CUP.

Rossini, Maria A. S. 2003. Aprender tem que ser gostoso. Rio de Janeiro: Vozes.

Schlatter, Margarete \& Garcez, Pedro M. 2012. Linguas adicionais na escola: aprendizagens colaborativas em inglês. Erechim, RS: Edelbra.

Silva, R. C. Machado e. 2014. Práticas e saberes de leitura entre jovens: signos éticos em questão. Apresentação de trabalho no XI CAAS (Congresso Argentino de Antropologia Social) Universidad Nacional de Rosário /Argentina.

2013. Do Ipê Roxo na Cidade Nova: possibilidades da experiência etnográfica em processos de aprendizagem escolares. (Disponível em: http://encuentrosetnograficos.weebly.com/uploads/7/4/6/5/7465057/ do_ip-_roxo_na_cidade_nova_possibilidades_da_experi-ncia etnogr-fica_em_processos_de_aprendizagem_escolares..pdf) Apresentação de trabalho no III Simposio Internacional Encuentros Etnográficos con niñas, niños, adolescentes y jóvenes en contextos educativos; Universidad Antonóma; Cidade: Oaxaca de Juárez México.

Signorini, Inês \& Cavalcanti, Marilda C. (orgs.). 1998. Linguística Aplicada e transdisciplinaridade. Campinas: Mercado de Letras. e para políticas de alfabetização e letramento. In: Marildes Marinho 
\& Gilcinei T. Carvalho. Orgs. Cultura, escrita e letramento. Belo Horizonte: Editora UFMG. p. 54-67.

Sousa SAntos, Boaventura. 1988. Um discurso sobre as ciências na transição para uma ciência pós- moderna. Estudos Avançados. 2/2:46-71.

SouzA, Silvana A. 2001. Gestão escolar compartilhada: democracia ou descompromisso?. 1. ed. São Paulo: Xamã Editora.

2013. Educação, trabalho voluntário e responsabilidade social. 1. ed. São Paulo: Xamã Editora.

StReEt, Brian 1984. Literacy in theory and practice. Cambridge University Press.

2010. Os novos estudos sobre o letramento: histórico e perspectivas. In: In: Marildes Marinho \& Gilcinei T. Carvalho. Orgs. Cultura, escrita e letramento. Belo Horizonte: Editora UFMG. p. 33-53.

Street, Brian. 2014. Letramentos sociais: Abordagens críticas do letramento no desenvolvimento, na etnografia e na educação. Trad. Marcos Bagno. São Paulo: Parábola.

ToRen, Christina. 1993. Making history: the significance of childhood cognition for a comparative anthropology of mind. Man. 28:461478.

VerTOVEC, S. 2007. Super-Diversity and Its Implications. Ethnic and Racial Studies. 30(6):1004-1054. 